\title{
Mentoring Processes in Higher Education: Perspectives of Junior Athletic Training Faculty Members
}

Sara Nottingham

University of New Mexico, nottingham@unm.edu

Stephanie M. Mazerolle

stephanie.m.singe@uconn.edu

Follow this and additional works at: https://nsuworks.nova.edu/ijahsp

Part of the Educational Leadership Commons, Higher Education Commons, and the Medicine and Health Sciences Commons

\section{Recommended Citation}

Nottingham S, Mazerolle SM. Mentoring Processes in Higher Education: Perspectives of Junior Athletic Training Faculty Members. The Internet Journal of Allied Health Sciences and Practice. 2018 Jan 01;16(4), Article 1.

This Manuscript is brought to you for free and open access by the College of Health Care Sciences at NSUWorks. It has been accepted for inclusion in Internet Journal of Allied Health Sciences and Practice by an authorized editor of NSUWorks. For more information, please contact nsuworks@nova.edu. 


\title{
Mentoring Processes in Higher Education: Perspectives of Junior Athletic Training Faculty Members
}

\begin{abstract}
Purpose: Mentorship is a valuable mechanism of socializing faculty members to higher education, but understanding of how mentoring relationships develop is limited. The purpose of this study was to seek a more complete understanding of how mentoring relationships develop for junior faculty members, and how these effective mentoring relationships can be fostered. Method: A qualitative, phenomenological design was used to examine junior athletic training faculty members' experiences with mentoring. Twenty athletic training faculty members: 14 women, 6 men, $32 \pm 3$ years of age and averaged $2.4 \pm 2.1$ years as a full-time faculty member in an accredited athletic training program participated in this study. Participants completed one telephone interview, which was audio-recorded and transcribed verbatim. Data were analyzed with an inductive phenomenological approach. Data saturation was obtained Trustworthiness strategies included peer review and the use of multi-analyst triangulation. Results: Junior faculty participated in informal and formal mentoring relationships that evolved over time, which aided their transition from doctoral student to full-time faculty member. Additionally, mentoring relationships were strengthened when participants took initiative, engaged in the relationship, and set clear goals. Mentors who exhibit good communication skills, willingness to participate, and genuine interest in the mentee are particularly valuable. Conclusions: Both formal and informal mentoring experiences appear to be valuable for junior faculty members, particularly informal relationships. If institutional mentoring programs are lacking then junior faculty should seek out additional mentoring opportunities. These findings also confirm existing literature on effective mentoring characteristics.
\end{abstract}

\section{Author Bio(s)}

Dr. Sara Nottingham, EdD, ATC is an Associate Professor in the Athletic Training program at the University of New Mexico and conducts research on clinical education, faculty development, and mentorship.

Dr. Stephanie Mazerolle, PhD, ATC, FNATA is an Associate Professor in the Department of Kinesiology at the University of Connecticut. She is a Fellow of the National Athletic Trainers' Association and conducts research on socialization, mentoring, and clinical education.

\section{Acknowledgements}

This study was funded by the National Athletic Trainers' Association Research and Education Foundation research grant \#1516EGP003. 


\title{
IJAHSP \\ The Internet Joưnal of Allied Health Sciences and Practice
}

Dedicated to allied health professional practice and education

Vol. 16 No. 4 ISSN 1540-580X

\section{Mentoring Processes in Higher Education: Perspectives of Junior Athletic Training Faculty Members}

\author{
Sara Nottingham, EdD, ATC 1 \\ Stephanie M. Mazerolle, PhD, ATC, FNATA2 \\ 1. University of New Mexico \\ 2. University of Connecticut \\ United States
}

\begin{abstract}
Purpose: Mentorship is a valuable mechanism of socializing faculty members to higher education, but understanding of how mentoring relationships develop is limited. The purpose of this study was to seek a more complete understanding of how mentoring relationships develop for junior faculty members and how these effective mentoring relationships can be fostered.

Method: A qualitative, phenomenological design was used to examine junior athletic training faculty members' experiences with mentoring. Twenty athletic training faculty members, 14 women, 6 men, $32 \pm 3$ years of age, and averaged $2.4 \pm 2.1$ years as a full-time faculty member in an accredited athletic training program, participated in this study. Participants completed one telephone interview, which was audio-recorded and transcribed verbatim. Data were analyzed with an inductive phenomenological approach. Data saturation was obtained. Trustworthiness strategies included peer review and the use of multianalyst triangulation. Results: Junior faculty participated in informal and formal mentoring relationships that evolved over time, which aided the transition from doctoral student to full-time faculty member. Additionally, mentoring relationships were strengthened when participants took initiative, engaged in the relationship, and set clear goals. Mentors who exhibit good communication skills, willingness to participate, and genuine interest in the mentee are particularly valuable. Conclusions: Both formal and informal mentoring experiences appear to be valuable for junior faculty members, particularly informal relationships. If institutional mentoring programs are lacking, then junior faculty should seek out additional mentoring opportunities. Effective mentoring characteristics in existing literature were confirmed by the findings.
\end{abstract}

\section{INTRODUCTION}

Faculty members have an important responsibility to their students, including teaching, advising, and mentoring students throughout their enrollment in their courses and programs. Additionally, faculty members have several other expectations to meet in their higher education environment, including conducting research, serving the university and profession, and engaging in academic culture. ${ }^{1-4}$ Faculty members become oriented to their responsibilities through professional socialization, which occurs during doctoral education and organizational socialization, which occurs after entry to the profession or organization. ${ }^{5,6}$ Previous researchers have identified the transition from doctoral student to full-time faculty member as a challenging time in which junior faculty members experience role strain and ambiguity of their expectations. ${ }^{5-7}$ Some have attributed this challenging role transition to a potential disconnect between doctoral education and faculty expectations. $2,3,8$ while others have cited inadequate organizational socialization and institutional support as a cause. ${ }^{9-13}$ Considering junior faculty members experience challenges transitioning to their full-time faculty roles, it is important to explore mechanisms to support them during this transition.

One strategy for supporting junior faculty is mentorship, or a relationship that is forged between two individuals with the purposes of providing guidance and support that is often meant to assist one person in his/her quest for a specific goal or purpose..$^{14,15}$ Faculty mentoring, therefore, is the process whereby a more senior faculty member (mentor) shares his or her experience, expertise, and advice regarding the tenants of higher education with a less experienced or pretenured faculty member (mentee). ${ }^{16}$ Faculty mentors can help less experienced faculty members navigate the tenure process, gain awareness of institutional policy 
and expectations, and help them develop effective skills to navigate role responsibilities, such as research and teaching. ${ }^{7}$ These mentoring relationships can develop through formal or informal mechanisms, ${ }^{17,18}$ and previous researchers have identified the positive effects of mentorship on research productivity and teaching development. ${ }^{18,19}$ Mentoring can assist in the development of role understanding, professional and organizational identity, and retention in the workplace due to reduction in role ambiguity. 17,20

Although there is a general understanding that mentoring is beneficial for the new, pre-tenured faculty member, there is only a superficial understanding of how these mentoring relationships develop for junior faculty members. Thus, the purpose of this study was to seek a more complete understanding of how mentoring relationships develop for junior faculty members and how these effective mentoring relationships can be fostered. This study was guided by the following research questions: How do effective mentoring relationships develop for junior faculty members transitioning to their full-time faculty roles? and How does mentorship influence the socialization of faculty members into their faculty roles?

\section{METHODS}

\section{Design}

The investigation was guided by a qualitative, phenomenological research design. ${ }^{21}$ Phenomenological research is used to gain an in-depth understanding of the topic of interest, in this case faculty mentoring, from those who have experienced the phenomenon. ${ }^{21}$ Institutional review board approval was obtained before the study began. This study was funded by the National Athletic Trainers' Association Research and Education Foundation research grant \#1516EGP003.

\section{Participants and Setting}

The researchers sought participants who recently completed their doctoral education and transitioned to a full-time faculty role. The target population of interest was athletic training faculty members who taught in Commission on Accreditation of Athletic Training Education (CAATE)-accredited programs. Inclusion criteria included completion of an academic doctoral degree program within the past 6 years and a rank no higher than assistant professor. Participants were recruited using purposeful and snowball sampling techniques beginning with the researchers' professional networks. ${ }^{21,22}$ The researchers represent two different size institutions, completed different types of doctoral degree programs, and represent different geographic areas of the country. Bracketing, or the explanation of the researchers' backgrounds, is a phenomenology strategy to promote transparency in the recruitment process. ${ }^{21}$ Thus, the researchers' background and sampling approaches were used for a diverse group of participants. Participant demographics and pseudonyms are displayed in Table 1.

Table 1. Participant Demographics

\begin{tabular}{|c|c|c|c|c|c|}
\hline $\begin{array}{c}\text { Participant } \\
\text { Pseudonym }\end{array}$ & Age & Sex & Doctoral Degree & $\begin{array}{c}\text { Current Institution Carnegie } \\
\text { Classification }{ }^{2}\end{array}$ & Experience as Full-Time Faculty \\
\hline Clare & 30 & $\mathrm{~F}$ & $\mathrm{PhD}$ & $\mathrm{R} 1$ & 2 \\
\hline Brenda & 32 & $\mathrm{~F}$ & $\mathrm{PhD}$ & $\mathrm{R} 2$ & 2 \\
\hline Andrea & 30 & $\mathrm{~F}$ & $\mathrm{PhD}$ & $\mathrm{R} 2$ & 2 \\
\hline Nat & 28 & $\mathrm{M}$ & $\mathrm{PhD}$ & $\mathrm{M} 1$ & 4 \\
\hline Donna & 36 & $\mathrm{~F}$ & $\mathrm{PhD}$ & $\mathrm{R} 1$ & 3 \\
\hline Steve & 32 & $\mathrm{M}$ & $\mathrm{PhD}$ & $\mathrm{R} 1$ & 1.5 \\
\hline Valerie & 31 & $\mathrm{~F}$ & $\mathrm{PhD}$ & $\mathrm{R} 1$ & 1 \\
\hline Brandon & 32 & $\mathrm{M}$ & $\mathrm{PhD}$ & $\mathrm{R} 2$ & 6 \\
\hline David & 33 & $\mathrm{M}$ & $\mathrm{PhD}$ & $\mathrm{R} 3$ & 2 \\
\hline Janet & 37 & $\mathrm{~F}$ & $\mathrm{EdD}$ & $\mathrm{BA}-\mathrm{AS}$ & 2 \\
\hline Shannen & 34 & $\mathrm{~F}$ & $\mathrm{PhD}$ & $\mathrm{M} 1$ & 9 \\
\hline Cindy & 30 & $\mathrm{~F}$ & $\mathrm{PhD}$ & $\mathrm{BA}-\mathrm{DF}$ & 1 \\
\hline Tori & 32 & $\mathrm{~F}$ & $\mathrm{PhD}$ & $\mathrm{M} 1$ & 1 \\
\hline Jennie & 34 & $\mathrm{~F}$ & $\mathrm{PhD}$ & $\mathrm{M} 1$ & 3 \\
\hline Gabrielle & 29 & $\mathrm{~F}$ & $\mathrm{PhD}$ & $\mathrm{M} 1$ & 4 \\
\hline Tiffani & 32 & $\mathrm{~F}$ & $\mathrm{PhD}$ & $\mathrm{M} 1$ & 5 months \\
\hline Hilary & 33 & $\mathrm{~F}$ & $\mathrm{PhD}$ & $\mathrm{M} 1$ & 3 months \\
\hline Kelly & 40 & $\mathrm{~F}$ & $\mathrm{PhD}$ & $\mathrm{M} 1$ & 3 months \\
\hline Dylan & 32 & $\mathrm{M}$ & $\mathrm{PhD}$ & $\mathrm{R} 2$ & $\mathrm{R} 3$ \\
\hline Jim & 27 & $\mathrm{M}$ & $\mathrm{PhD}$ & $\mathrm{R} 3$ & 2 \\
\hline
\end{tabular}

Note: a Carnegie Classifications of Higher Education: 
R1: Doctoral Universities-Highest research activity.

R2: Doctoral Universities-Higher research activity.

R3: Doctoral Universities-Moderate research activity.

M1: Master's Colleges and Universities-Larger programs.

M2: Master's Colleges and Universities-Medium programs.

M3: Master's Colleges and Universities-Smaller programs.

${ }^{b}$ Carnegie Classifications of Higher Education:

BA-AS: Baccalaureate Colleges-Arts \& Sciences Focus.

BA-DF: Baccalaureate Colleges-Diverse Fields.

\section{Instrumentation}

The researchers developed a semi-structured interview guide specifically for this study. Semi-structured interviews were used for researchers to obtain specific information from participants but still have flexibility in the conversation to gain appreciation for participants' individual experiences and backgrounds. ${ }^{22}$ This guide was developed based on principles of qualitative inquiry and previous research on related topics. ${ }^{6,7}$ The interview guide was peer-reviewed by 2 qualitative researchers, who critiqued the content, wording, and order of questions. ${ }^{23}$ The guide was revised based on their suggestions and piloted with 2 individuals who met the inclusion criteria for the study. They provided minor suggestions regarding order of questions. At that time, the interview guide was finalized for use with participants.

Interview Guide. See the list of questions used in the interview:

1. Do you currently have any mentors? If so, please describe.

2. The mentors you shared, are those mentors internal and/or external to your current position/institution?

3. How did these mentoring relationships develop?

a. eg, formal, informal

b. If formal, can you share how you were paired with the mentor? How did you learn about the mentor program? Was it voluntary? How long was the formal aspect of the program? Can you summarize your overall experiences in the formal program?

c. If informal, how long have the informal relationships lasted?

d. If they have both, how are they similar or different?

4. Please describe characteristics of an effective faculty mentor.

5. Please describe characteristics of an ineffective faculty mentor.

6. What advice would you give to someone who mentors junior faculty members?

7. Is there any advice you would share for a doctoral student regarding mentorship relationships, and being prepared for a faculty role?

8. Is there anything else you would add to the interview today, as it relates to mentorship or your development as a faculty member?

\section{Data Collection Procedures}

Participants were recruited via an email, which provided an overview of the study and a request for participation. After expressing interest in participating, the researchers scheduled a telephone interview. The interview began with a description of the study, followed by a verbal consent statement to be audio recorded. Once the participant agreed to participate and to be audio recorded, the interview was completed. At that time interviews were transcribed by a professional transcription company, blinded, and prepared for data analysis.

\section{Data Analysis Procedures}

Researchers independently analyzed interview transcripts using a qualitative, phenomenological approach. ${ }^{21}$ Data analysis began with a global review of each transcript and a notation of key statements. Interviews were then reread several times, and the researchers continually identified and labels key statements, known as codes. ${ }^{21}$ Codes were then organized into categories and resulting themes with supporting quotes. At that time, researchers compared findings and reached consensus on the final themes and supporting quotes. ${ }^{21,23}$ The researchers agreed that data saturation had been obtained with the 20 participants and no additional data needed to be collected. ${ }^{21}$ The researchers then asked 2 peer reviewers to examine the findings to confirm accurate representation of participants' statements. ${ }^{23}$ These qualitative researchers confirmed the findings, and the study was deemed complete.

\section{Trustworthiness}

(c) The Internet Journal of Allied Health Sciences and Practice, 2018 
Several mechanisms of trustworthiness were used throughout the data collection and analysis process. Two peer reviewers were used early in the process to review the interview guides to identify any leading questions and ensure the questions matched the study objectives. ${ }^{23}$ Peer reviewers were then integrated again at the end of the data analysis process to confirm credibility of the findings. ${ }^{23}$ Multiple researchers independently analyzed data, reducing research bias in the analysis process. ${ }^{23}$ Lastly, the researchers used a bracketing strategy to disclose their background. ${ }^{21}$

\section{RESULTS}

Analysis of interview data showed 2 themes related to faculty mentoring: development and evolution of mentoring and facilitation of effective mentoring. Participants described participating in mentoring relationships that formed through different mechanisms and evolved over time to provide ongoing support. Secondly, they described characteristics of effective mentoring and provided suggestions for facilitating effective mentoring relationships for junior faculty members.

\section{Development of Mentoring}

Analysis showed that participants engaged in both formal and informal mentoring relationships. Informal mentoring was the predominant type of mentoring relationship, yet both were shared as part of the faculty culture in higher education. These mentoring relationships also evolved over time, adapting to the needs of the mentees as they developed in their faculty roles (Figure 1).

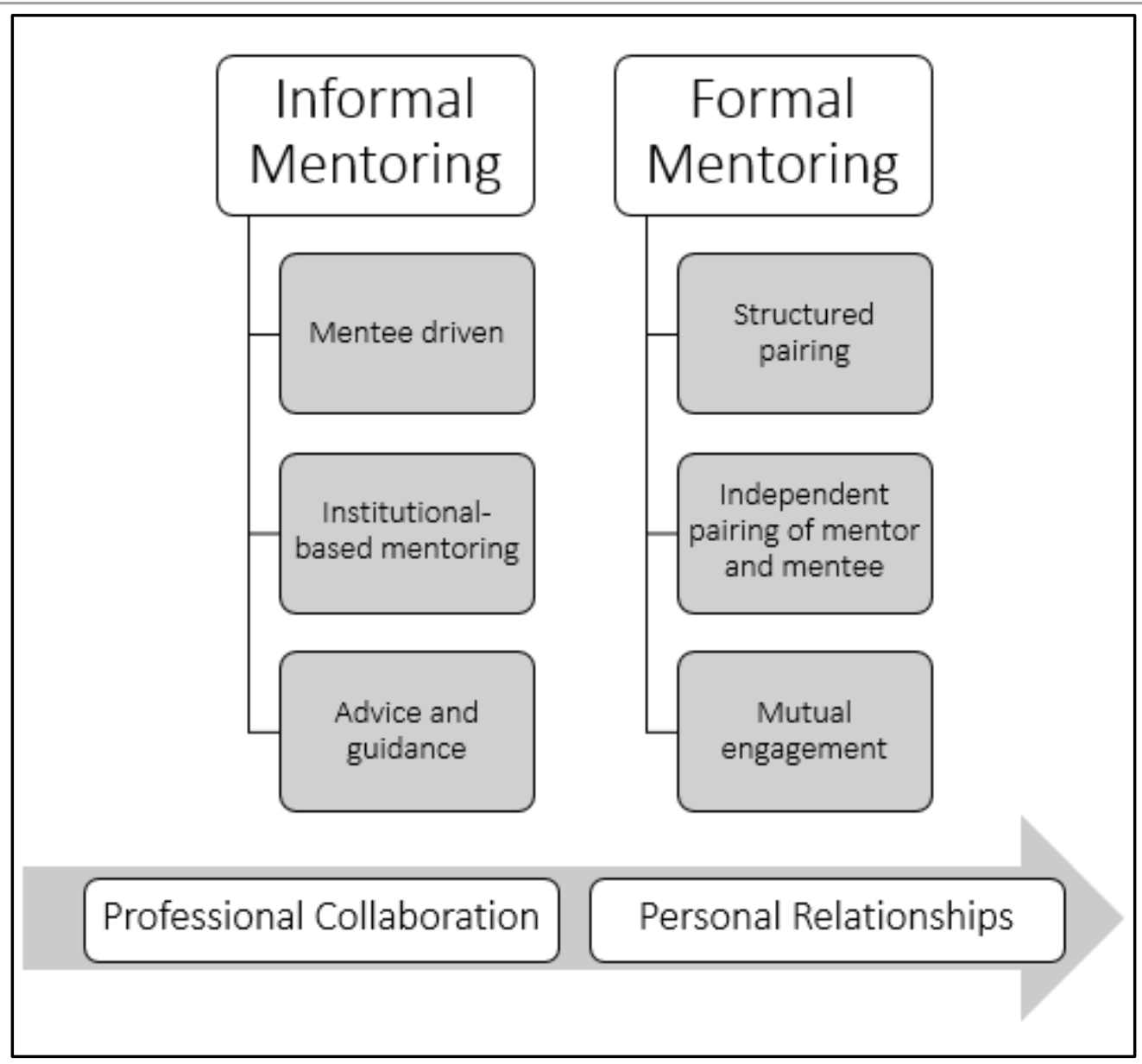

Figure 1. Mentoring Relationships

Informal Mentoring. All participants in this study had informal mentors. These mentors often emerged from within their current institution from a need for assistance or organically occurred from regular interactions. As Cindy described, "I do have a mentor in my Department Chair. She's been great at really just being available and helpful to me, and anything that comes along in which my inexperience could potentially be aided by her experience." Like several other participants, she described the organic 
development of this mentoring relationship: "I think it was kind of just naturally, since it's a small department. We're a fairly closeknit faculty that, it kind of just happened naturally." These informal mentoring relationships often developed with departments because junior faculty mentors felt they needed advice and support. As Donna stated, "Unofficially, I think all of the other senior faculty members in my program or department are mentors. I think they kind of developed out of necessity a little bit." Gabrielle noted a similar relationship with experienced faculty in her department: "I really just approached them and asked if they'd be willing to meet with me periodically so that I could bounce some ideas off of them, because we had similar goals essentially. I can emulate what they're doing and therefore also be successful."

These informal mentoring relationships within institutions usually occurred because junior faculty members felt like they needed advice from a more experienced individual. As Nat described, "They kind of [developed] organically for being a new faculty member. I think it just developed out of my seeking out of a person that could assist me in questions or small day to day tasks or kind of my own professional development." He elaborated that he identified mentors in areas he needed help: "So, it's just kind of me recognizing where I needed some help and then going out and finding the right person to help me with that." Steve echoed that his mentoring relationships are also based on needs: "My informal relationships are more needs based. So, that's when l've got a question or concern. Something pops up that l'm unsure of or could use some direction." Shannen described that she also has informal mentors, but those individuals sought out her and other junior faculty to help them during their transition to faculty:

There are other faculty that are more informal in the department that help make sure that we, as junior faculty, stay on top of what we're supposed to be doing. My department chair is really good, helpful with that. And he actually has been a little more helpful in the social aspect of navigating the administration. I think with my program director, that mentorship was just a natural. That relationship just came like organically. Just kept bouncing ideas off of him from a departmental and how things are done.

Additional informal mentoring relationships originated from similar research interests between faculty. These similar interests often branched out beyond a faculty member's immediate athletic training program, such as Brandon's case: "The mentor I have here at the institution, at the med school, has similar research interests and we use similar equipment, so that's kind of how that started." Likewise, Dylan described identifying mentors beyond his program with similar research interests: "A mentorship from just a research standpoint, there are a couple of faculty members in Exercise Physiology, which is housed within the same department, that should we go to them and ask questions, they would make time for us and help us, but nothing from an official standpoint."

Formal Mentoring. Thirteen of the participants participated in a formal mentoring experience as a full-time faculty member. Some of these were internal/institutional, and others were formal professional mentoring programs. Several faculty members described internal institutional mentoring programs. As Kelly described, "There's a program for the new hires. It's like a mentorship group where a couple of the established faculty set up meetings and things to help us out. And they're available for questions." Andrea participated in a formal institutional mentor program that was required for those who submitted grants: "I've received some internal grant funding through [my institution] and the faculty opportunity awards require as a new investigator that I have a mentor on the project and she has served as a mentor in that capacity. Steve spoke about how formal mentoring is set up in his university: "We get assigned a primary mentor and then two secondary mentors prior to reappointment."

Unfortunately, several faculty members noted their institutional mentoring programs were not very helpful. David described: "My institution has a faculty mentor program where they connect you with a tenured faculty in the department. It sounds nice, but there's not much mentorship that's occurred." Shannen also felt that she did not gain much out of her formal institutional mentor program: "Our university does have a mentorship program like a senior/junior. I did that for 2 years and they usually pick someone outside of your discipline and my mentor really never met. It was a group mentorship. I wasn't really happy with that."

Several participants had also engaged in a formal professional mentoring program hosted by the National Athletic Trainers' Association (NATA) Research \& Education Foundation. As Cindy noted, "Formally, l'm participating in the Research Mentorship Program through the NATA Research and Education Foundation." Tori was also a participant, describing her interest in participating: "Our national governing body put a call out with some descriptors, and I felt that I fit those descriptions, and I had been looking internally for somebody who I felt had the time to dedicate to providing me with mentoring in my current situation." Clare also described her process of signing up for the program:

Formally, I'm enrolled in NATA research education foundation mentoring program. We filled out this form that said what we expected out of a mentoring program, what we thought we'd need help with, and then they paired us with someone in the field that they thought could help with that or served in similar roles or has kind of where dream jobs may be.

(C) The Internet Journal of Allied Health Sciences and Practice, 2018 
Faculty members generally sought participation in the NATA Foundation program because they wanted a mentor in the athletic training profession, such as Steve, who described

I participated in the NATA mentorship, research mentorship program a few years ago. And so, I still touch base with my mentor every once in a while from that program as well. From a pairing perspective, it just made sense to have me paired with someone who is already experiencing athletic training.

Through these different formal mechanisms, junior faculty members were often able to find the mentors they needed to support their professional development.

Evolution of Mentoring Relationships. Participants described that after the initial development of mentoring relationships, either from a formal or informal means, their relationships often evolved over time. Oftentimes, this relationship transformed from a hierarchical, formal interaction to a more collaborative relationship. Usually, this relationship was with a former doctoral advisor, who faculty stayed in touch after taking on the first faculty role. Jim described his current relationship with his formal doctoral mentor as collaborative: "A mutual mentorship between the two of us, I'm sure he learned just as much from me as I learned from him. And it's a give and take, back and forth. It didn't feel like a hierarchy, more like a mutual relationship in that we're colleagues and he could be more of a mentor because of that, not as much of again hierarchy type idea." Nat described his evolving relationship with his doctoral mentor: "I think my doctoral mentor, l've worked with him for a very long time and we've, the relationship outside of the realm like we're pretty good friends, so I think having that as a resource of just going to him. A lot of personal questions that he's definitely been a great support system to have." Several participants described still being able to use their doctoral advisor as a resource, such as Cindy described, "Once I finished the doctoral program, the communication was clearly far less, but again, I still feel that they are a resource to me. Maybe a resource is a better word than mentors." Donna also said: "It feels like you never lose your doctoral mentor or doctoral advisor. I can always go back to her for things."

In addition to a collaborative relationship, one that focused on productivity and advancement of professional goals, other faculty realized that the formal aspect of the mentoring relationship turned into a more personal one: a friendship. As Clare stated, "The high school athletic trainer we've kept in touch ever since through undergrad, grad school, kind of developed into a friendship, but I just felt like she was somebody that I could call when I had questions on classes or questions on athletes." Tori described a similar relationship with a former preceptor:

One [mentor] was actually one of my preceptors when I went through undergrad, and I saw this individual transition from completely clinical into more of an academic role. And now, he is a program director, and completely academic. And he's just the one that has just continued to remain in that role, so we just developed a good friendship. He's been through everything that I'm about to go through as far as a program director coming up for an accreditation. So, I just, I rely on him because he's been through all of those scenarios.

The athletic training faculty members described mentoring relationships that developed into friendships over time, providing an additional mechanism of support. Hilary described an important mentor to her: "This person was actually my doctoral mentor when I was a doctoral student, but it's someone who I have remained close to both personal and professional manner." She went on to describe "with her it's really more of a maturity and personality kind of match," which facilitates a different dynamic with other mentors: "we all kind of feel the same pressures and can commiserate and have similar challenges and I think, I don't even know if it would truly be considered kind of a mentor/mentee more than someone to commiserate with." Janet also described that for her, friends and mentors are interchangeable: "I have a couple friends from graduate school that I still keep in contact with to get their opinions." Likewise, Tori referred mentors as both friends and colleagues: "the other two that I speak to on a regular basis are, they're definitely colleagues of mine. And I consider them my friends." The participants' perspectives suggest that mentoring not only takes a formal professional dimension, but also has an important aspect of friendship.

Facilitation of Effective Mentoring. The theme facilitation of effective mentoring was supported by two categories: effective mentoring characteristics and strategies for facilitating faculty mentorship. Junior faculty members perceived that effective mentoring was grounded in their alignment of interests and experience with the mentor and effective interpersonal attributes. Effective mentoring was facilitated by initiative, engagement, and effective communication by both the mentor and mentee. These categories are described below and summarized in Figure 2.

(C) The Internet Journal of Allied Health Sciences and Practice, 2018 


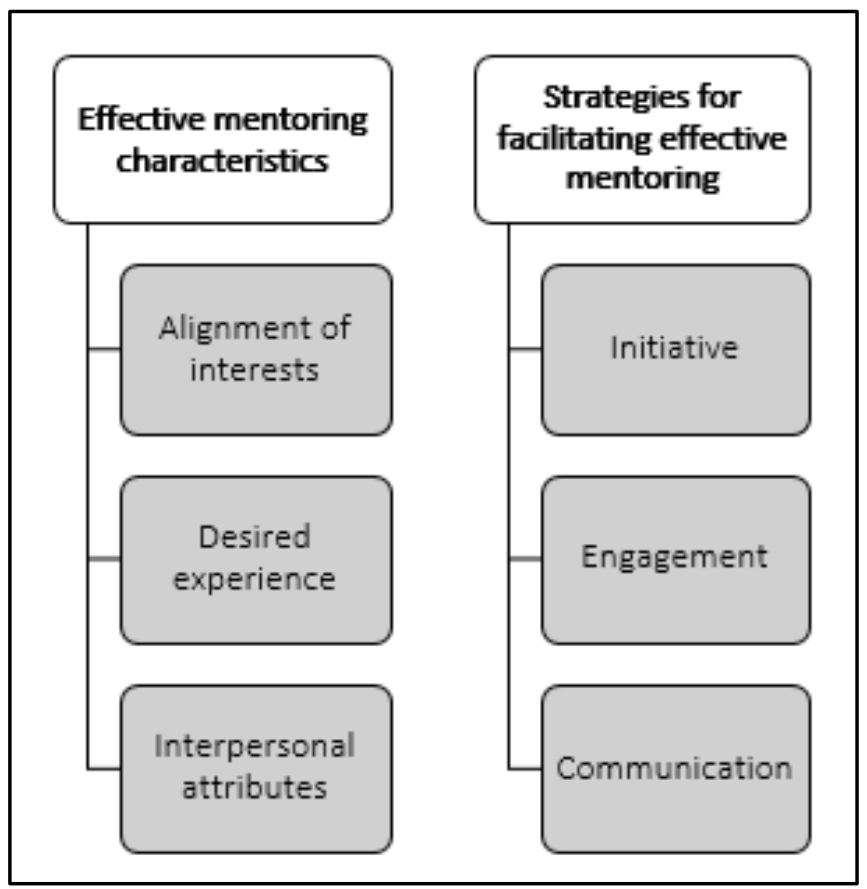

Figure 2. Facilitation of Effective Mentoring Relationships for Faculty Members

Effective Mentoring Characteristics. Junior faculty members commented on several aspects that made their mentoring experiences valuable. Several effective mentoring characteristics were found, including (1) alignment of interests, (2) experience desirable to the mentee, and (3) interpersonal attributes.

Alignment of Interests. In addition to understanding how their mentoring experiences developed, we also sought to understand effective characteristics of these mentoring experiences. Junior faculty members commented on several aspects that made their mentoring experiences valuable. First, participants described that some of their most effective mentoring relationships were those in which mentor and mentee interests were highly aligned. As Jim described, "I want to be productive here. I want to do research. So, if I have a faculty mentor that thought research was a joke or it's oh, you really need to do enough to skirt by, that's not what l'm looking for either. I want it to be someone that can drive me forward and help show me those opportunities." Participants described that good mentors understood the mentee's needs and situation. They identified the mentee as an individual and adapted their mentoring to that person. As Valerie commented, "getting the time to get to know somebody and know and understand what they're trying to achieve and then also understand the way and method in which you need to communicate and support them." Likewise, Hilary described that effective mentors: "Recognize traits that other people have and being able to respond and adapt to those in order to recognize this person they might need more in this area and less in this are."

Desired Experience. Junior faculty noted that it was important to have mentors who were experienced and knowledgeable, particularly in ways that matched junior faculty members' goals. When asked to describe characteristics of effective mentors, Gabrielle stated, "Having experience. I think that's one of the reasons that people seek out mentors is that they've done what you're trying to do. And they have experience and they've been successful at it." Similarly, Steve said, "I think someone who's actually got experience. So, someone who has been doing or is doing what you're hoping to do in the future really helps. I think having some experience to draw from is really important. It would be hard to be a mentor if you didn't have that." David elaborated that experienced faculty act as role models to learn from: "It's also vital for them to have those experiences for which you want to, and those goals for which you want to achieve. So, those mentors need to have been there and done that. I think that's important because then you can learn from their mistakes or their successes."

Interpersonal Attributes. Junior faculty members desired that their mentors demonstrated effective qualities, such as engagement, willingness to participate, and availability to their mentors. Jennie said, "I think that you have to show that you're willing to mentor." Gabrielle echoed, "I think one of the things that makes them ineffective is being unavailable. And/or being distracted during your time with them." Cindy noted that ineffective mentors as "Not being, not having the willingness to make themselves available," emphasizing that in order to mentor effectively, one has to be interested and willing to engage in mentoring. 
Desirable qualities of mentors also included demonstrating patience, respect, and good communication skills. Tiffani summarized a good mentor as being "Someone who's caring. Someone who invests time in their student. Someone who listens, I think, and gives good advice." Similarly, Jennie stated, "Kind, available, professional, honest." Dylan commented, "a good listener and someone with good communications." Cindy elaborated on effective communication styles: "An effective mentor is somebody who has effective communication techniques. Somebody who is available, but also somebody who can set boundaries. Effective leadership style that also compliments either the leadership style or the learning style of the mentee."

Mentees also described that honesty and delivering straightforward, constructive feedback was an important characteristic of mentors. Gabrielle pointed out "Being honest is important. There's hard conversations that you have to have. But, I think if the mentor is honest that's usually more helpful than if they're just telling you something that you want to hear." Steve made a similar comment stating, "I think a lot of times mentors are afraid to give you it straight. They feel like they want to maintain a friendly relationship or they want to maintain a positive relationship. So, they try to sugar coat or make it easier. I would much rather have straightforward and consistent honest feedback." Junior faculty noted this balance of "respect" (Shannen), "trust" (Janet), and "honesty" (Donna) were important characteristics for mentors to exhibit.

Strategies for Facilitating Faculty Mentorship. Participants provided advice for junior and experienced faculty members to encourage effective mentoring relationships. The focus of the advice was around initiative, engagement, and communication.

Initiative. Junior faculty members suggested that new faculty should actively seek out mentors to support them in their new role. Some suggested this support should begin as soon as the interview, which Andrea noted: "When you are looking at jobs, you have to keep in mind when you're doing your interviewing who is here that could be my mentor? I think that that was so critical to me, because ultimately my success depends upon if I have a support system around me that allows me to be successful." Tori also recommended to junior faculty: "That you need to act. So, when you go into an interview and use the term formal, what formal mentorships are set up here?" Steve elaborated on the idea of seeking out mentors early:

I think during your interview process and during your job negotiations and starting your position, mentorship should absolutely be something that you are asking about. And getting more detail and understanding the structure of before you sign on any dotted line. Or before you commit to doing anything. I think as a junior faculty, it's very hard, especially at a new institution, to get yourself up and running if you don't have, whether it's informal or formal, mentorship that you can rely on for some help. Don't be afraid to be proactive about it. I think if new faculty members feel like they're not getting the mentorship they're supposed to, there's absolutely nothing wrong with stepping up and saying something about it.

Additionally, several faculty encouraged new faculty members to seek out mentors once they start their new positions. Clare recommended, "Find people in your department that you can collaborate with also to help on existing studies or branch off of projects that are going on." Jim echoed, "Actively search out for someone in your new position and make it clear what you need or how you need it." Likewise, both Jennie and Gabrielle said, "Find a mentor for themselves," and "If you don't have a mentor to seek one out and you can actually ask if that person will be your mentor." After finding a mentor, faculty should "Take advantage of having a mentor and asking questions. Maybe meeting regularly just to have conversations about how things are going" (Hilary).

Advice from junior faculty was also directed towards experienced faculty. Mentees particularly encouraged mentors and experienced faculty to seek out junior faculty to help. Brenda said experienced faculty should "Look for people to mentor. You've already been successful. Look for other people who need help. Spread the wealth." Donna believed it is experienced faculty members' "professional obligation to be willing to mentor young faculty members." She elaborated by saying, "I would want them to remember what it was like when they were first hired, and they didn't graduate from their doctoral program knowing all of answers about navigating the system." David requested that experienced faculty "Be open to passing it forward and becoming a mentor."

Engagement. After developing mentoring relationships, junior faculty encouraged both mentors and mentees to engage in the mentoring relationships. Tiffani encouraged junior faculty members to "absorb as much as you can from your mentor. Ask questions, communicate with them, seek out answers to questions that you have." Several faculty members thought experienced faculty could be more proactive with junior faculty members, often by simply checking in and reach out to junior faculty to demonstrate availability for mentoring. Steve thought, "I think mentors have to be a little proactive" because "being a little proactive shows real investment in the relationship." Janet also encouraged senior faculty members to reach out to their junior counterparts: "Make yourself available. Sometimes that may often mean that you're reaching out to them." Hilary described, "Just take a second and ask how they're doing. I mean, sometimes that can just go a long way because that's what opens the door for conversation.

(C) The Internet Journal of Allied Health Sciences and Practice, 2018 
I think that's really kind of the gateway for everything else to kind of start rolling." Likewise, Jennie recommended that experience faculty mentors:

Check in with [junior faculty] because as a mentee, especially if you're a junior faculty and you're not sure about what you're doing or you're probably having questions but feeling like everybody else knows what they're doing. I would ask that the mentor would advise for them to just check in regularly to make sure that the mentee knows that they're around. And that they are available if they have questions or want to sit and talk about things.

Communication. Participants recommended that those engaged in mentoring relationships set goals and expectations early and communicate regularly to foster an effective relationship. As Jennie noted, "It's important to set goals. For a junior faculty, I think it's important to have a very clear plan with your mentor." Tori recommended, "Have a plan, set, schedule the meeting just like it's class, have a plan and a goal. What are we working towards? And then hold that person accountable." Dylan emphasized that "an open line of communication, laying out those expectations early" helped make mentoring effective. Brenda suggested that when establishing a new mentoring relationships, mentors and mentees should "try and sit down in the beginning and be clear on expectations" because "setting expectations, setting deadlines, measurable, that really helps." Individuals who participated in formal mentoring noted this was a benefit to such a program, the opportunity and structure to define interests and goals in participating:

I think, one of the things that really drew me with the NATA Mentorship Program is it gives you the opportunity to list out what things you're looking for so you can be specific, whether it being research or teaching based or mentoring students or anything else, so having that option to hopefully prepare someone that can provide guidance specifically to what they're looking for. (Dylan)

Considering setting clear goals appears to be an important component of effective mentoring; mentors and mentees should be encouraged to structure their mentoring experiences and communicate their needs regardless of whether the mentoring relationship is formal or informal.

\section{DISCUSSION}

The transition from doctoral student to full-time faculty member has been identified as a challenging time in which junior faculty members are attempting to learn their roles and expectations within academia. ${ }^{6}$ With the results of this study, we demonstrated that junior faculty members perceive mentoring to be a helpful mechanism of organizational socialization or the process of learning the organizational culture and job expectations. Junior faculty engaged in multiple types of formal and informal mentoring relationships found some of which were more helpful than others. Additionally, participants identified characteristics and strategies of effective mentoring. These findings present a new understanding of how mentoring relationships are initiated and fostered for junior athletic training faculty members.

\section{Development of Mentoring}

In this study, junior faculty members participated in both formal and informal mentoring relationships that developed in different ways. Several participants described that their institutions provided formal mentoring programs for junior faculty members.Conceptually, formal mentoring relationships are built upon goals and objectives and can include planned communication and frequent meetings. ${ }^{17}$ As a derivative of organizational policy or structure, the formal relationships are short lived and designed to provide role understanding ${ }^{17}$ and act as a springboard for long-lasting relationships. ${ }^{13}$ Participants had mixed experiences with their formal mentoring experiences with their biggest value coming from connecting junior faculty to more experienced individuals throughout the university. Others described that these experiences were unproductive or short lived, making them generally unhelpful. Previous researchers have also found conflicting findings with the impact of formal institutional mentoring programs with some finding positive outcomes, such as increased research productivity and job satisfaction. ${ }^{15,19}$ In contrast, other faculty members have described that these mentoring programs lack commitment or productivity, preferring informal mentoring relationships because they feel less forced. ${ }^{13}$

Several participants voluntarily sought out a professional formal mentoring program, which were designed to connect athletic training faculty members with similar research interests and provide support for their faculty responsibilities. ${ }^{24}$ Those who participated in this program generally spoke positively of the experience. In particular, they appreciated the connection with a faculty member specific to their discipline and research interests. Having similar interests has been noted as a characteristic of effective mentoring relationships, ${ }^{14}$ which aligns with these participants' interests in the program. Junior faculty members who sought participation in this program did so because they desired additional support they did not believe they received within their institution. Thus, it appears professional formal mentoring programs are valuable resources for junior faculty members. The value

(C) The Internet Journal of Allied Health Sciences and Practice, 2018 
of having multiple mentors has been demonstrated in academia; therefore, faculty members may consider seeking out a variety of formal mentoring opportunities to support their transition to their faculty role. ${ }^{13}$

Regardless of participation in a formal mentoring experience, all of the participants sought out informal mentors. As previous researchers have noted, informal mentoring organically developed for many of these participants due to their regular interactions within their departments and universities. ${ }^{17}$ The relationship is often forged by an individual seeking out the other for purposes of facilitating professional development. ${ }^{25}$ Junior faculty members in this study often sought out mentors because they needed support and guidance from someone within their institution. These informal mentoring relationships were valuable in helping them navigate institutional expectations and resources as previous researchers have noted. ${ }^{7}$ Kram has advocated that informal mentoring is superior to formal mentoring because it naturally develops and is not forced, and academic medicine faculty members echoed this sentiment. ${ }^{19,26}$ As it appears there are individual preferences to formal and informal mentoring, faculty members should be resourceful and seek out and take advantage of mentoring relationships that meet their individual needs. Novice faculty members should be encouraged to seek out more experienced faculty mentors within their departments and institutions to support them during their transition.

Interestingly, participants described that their mentoring relationships often evolved over time. Regardless of whether they developed formally or informally, participants described that their relationships often began as a hierarchical mentor-mentee relationship and changed into more of a collaborative and friendly relationship. Previous researchers have noted that mentoring relationships, particularly informal, are grounded in similar personality traits and become mutually beneficial over time. ${ }^{17,27,28}$ Likewise, formal mentoring can be strengthened with personal connections and similarities, such as having similar family structures and personal interests. ${ }^{29}$ Knowing that mentoring is a valuable source of support for faculty members, it is encouraging that these participants described relationships that were long-lasting and mutually beneficial.

\section{Facilitating Effective Mentoring}

Participants' statements about effective and ineffective characteristics of mentoring were in alignment with previous literature, emphasizing the importance of demonstrating willingness, availability, and common interests in mentoring relationships. $14,19,30$ Effective mentors provide honest, straightforward feedback about a mentee's progress, which these participants also noted. ${ }^{19}$ Like the findings of Straus et al, junior faculty members in this study wanted their mentors to be a trusted resource, not someone who held their hand or was too overbearing. ${ }^{19}$

Effective mentoring for these participants was also grounded in initiative, engagement, and concrete goals. While previous researchers in higher education have identified similar key characteristics of mentoring, 14,19 junior faculty members spoke extensively about the need for fellow junior faculty to seek out mentors. This need included asking about mentoring opportunities during job interviews and purposefully seeking out mentors and mentoring programs upon taking a new job. Doctoral students and new faculty members should be aware of the importance of initiating mentoring and seeking out these opportunities. Likewise, junior faculty members described that initiative by senior faculty members was also very helpful during their transition to a new faculty position. They described that oftentimes junior faculty members do not know of the available resources or when help is needed and that small gestures by senior faculty, such as asking how they are doing and offering advice and support, were tremendously beneficial. With these findings, we suggest that the initial acts toward mentorship, however minor they may appear, are significant during a new faculty member's role transition.

Lastly, participants noted the importance of setting clear goals and expectations in any mentoring relationship. Setting goals helps to focus mentoring and facilitates communication and is important for both formal ${ }^{29}$ and informal mentoring relationships. ${ }^{19}$ Researchers in pharmacy programs have developed formal institutional mentoring programs with specific goals and outcomes to help facilitate effective mentoring relationships for junior pharmacy faculty. 15,31 We found that with the findings of this study and existing literature, the importance of goal setting and communication for any faculty mentoring relationship was emphasized. Additional recommendations based on the findings of this study are listed in Table 2. 
Table 2. Recommendations for Facilitating Effective Faculty Mentoring

\begin{tabular}{lll}
\hline \multicolumn{1}{c}{ Advice for Junior Faculty } & \multicolumn{1}{c}{ Advice for Senior Faculty } \\
\hline $\begin{array}{l}\text { 1. Seek out mentoring opportunities within and } \\
\text { beyond your institution, both formal and informal. }\end{array}$ & 1. $\begin{array}{l}\text { Be available as a resource for junior faculty members } \\
\text { and actively engage in mentoring them. }\end{array}$ \\
$\begin{array}{ll}\text { 2. Demonstrate effective mentoring characteristics, } \\
\text { including effective communication, willingness to }\end{array}$ & $\begin{array}{l}\text { 2. } \\
\text { Provide honest, detailed feedback about a faculty } \\
\text { member's performance. }\end{array}$ \\
$\begin{array}{ll}\text { participate, and engagement in thb relationship. } \\
\text { Communicate your needs for mentoring and setgoals } \\
\text { with your mentor. }\end{array}$ & $\begin{array}{l}\text { 3. } \\
\text { Engage in mentoring only if you are genuinely interested } \\
\text { in the success of the junior faculty member and have } \\
\text { the time to commit to the relationship. }\end{array}$
\end{tabular}

\section{LIMITATIONS AND FUTURE DIRECTIONS}

The sample of this study was junior athletic training faculty members. Therefore, the findings may not apply to broader academic disciplines. Future researchers should examine the development of mentoring for other disciplines and professions, particularly those without a professional formal mentoring program to further understand mentoring resources for junior faculty. We examined faculty mentoring only from the lens of the mentee's perspective; therefore, mentors may provide additional insight about the development of mentoring. Additionally, because we focused on individuals who recently transitioned from their doctoral experience, most participants were within the first few years of their faculty position. Their perspectives may change over time; therefore, future researchers should examine faculty mentoring from a broader perspective. Additionally, participants described varied experiences with formal institutional mentoring programs, ranging from very positive to not functioning. Knowing the importance of mentoring for junior faculty would be valuable to investigate these faculty mentoring programs more extensively to identify effective and ineffective characteristics of these programs. Additionally, it would be valuable to examine mentoring for faculty in both tenure-track and non-tenure-track positions to determine if any variations in mentoring support exist for these different positions.

\section{CONCLUSIONS}

Junior faculty mentors identified mentoring as a valuable source of support during their transition from doctoral student to full-time faculty member. Most faculty members relied on both informal and formal mentoring relationships. Participants had both positive and negative experiences with formal mentoring, but those who volunteered to participate in a professional formal mentoring program found that to be a helpful resource that balanced out a lack of resources within their institutions. Considering informal mentoring is extremely valuable for faculty members, both junior and senior faculty members are encouraged to seek out and foster these relationships within their institutions. Mentoring relationships are strengthened by ongoing engagement, communication, and common goals, thus faculty members should consider these effective characteristics when developing mentoring relationships.

\section{REFERENCES}

1. Mazerolle SM, Bowman TG, Klossner J. Perceptions of tenure and promotion guidelines and criteria among athletic training doctoral students. IJAHSP. 2017;15(3):Article 5.

2. Hertel J, West TF, Buckley WE, Denegar CR. Educational history, employment characteristics, and desired competencies of doctoral-educated athletic trainers. J Athl Train. 2001;36(1):49-57. [PMID: 12937515]

3. Dewald L, Walsh K. Tenure track athletic training educators: Are they being set up to fail? Athl Train Educ J. 2009;4:144-9.

4. Payne EK, Berry DC. From graduate student to professor: Reflection on the transition and tips for those who follow. Athl Train Educ J. 2014;9(2):87-93.

5. Mazerolle SM, Bowman TG, Klossner JC. An analysis of doctoral students' perceptions of mentorship during their doctoral studies. Athl Train Educ J. 2015;10(3):227-35.

6. Mazerolle SM, Barrett JL, Nottingham SL. Examining the factors that facilitate athletic training faculty socialization into higher education. Athl Train Educ J. 2016;11(4):208-18.

7. Nottingham SL, Mazerolle SM, Barrett JL. Roles of mentoring for novice athletic training faculty members. Athl Train Educ J. 2017:12(4):234-43.

8. Payne EK, Walker SE, Mazerolle SM. Exploring athletic training educators' development as teachers. Athl Train Educ J. 2017;12(2):134-45.

9. Austin A. Creating a bridge to the future: preparing new faculty to face changing expectations in a shifting context. Rev High Educ. 2002;26(2):119-44.

10. Gaff JG. Preparing Future Faculty and Doctoral Education. Change. 2002;34(6):4. 
11. Smensy AL, Williams JS, Brazeau GA, Weber RJ, Matthews HW, Das SK. Barriers to scholarship in dentistry, medicine, nursing, and pharmacy practice faculty. Am J Pharm Educ. 2007;71(5):Article 91. [PMID: 17998988]

12. Tierney W, Rhoads R. Faculty Socialization as Cultural Process: A Mirror of Institutional Commitment. Washington D.C.: The George Washington University; 1993.

13. Zellers $\mathrm{D}$, Howard V, Barcic M. Faculty mentoring programs: reenvisioning rather than reinventing the wheel. Rev Educ Res. 2008;78(3):552-88.

14. Barrett JL, Mazerolle SM, Nottingham SL. Attributes of effective mentoring relationships for novice faculty members: Perspectives of mentors and mentees. Athl Train Educ J. 2017;12(2):152-62.

15. Fuller $\mathrm{K}$, Maniscalco-Feichtl M, Droege M. The role of the mentor in retaining junior pharmacy faculty members. Am J Pharm Educ. 2008;72(2):1-5. [PMID: 18496925]

16. Austin A. Preparing the next generation of faculty. Higher Educ. 2002;73(1):94-122.

17. Inzer L, Crawford C. A review of formal and informal mentoring: Processes, problems, and design. J Leadership Educ. 2005;4(1):31-50.

18. Sambunjak D, Straus S, Marusic A. Mentoring in academic medicine: A systematic review. JAMA. 2006;296(9):110315. [PMID: 16954490]

19. Straus S, Chatur F, Taylor M. Issues in the mentor-mentee relationship in academic medicine: A qualitative study. Acad Med. 2009;84(1):135-9. [PMID: 19116493]

20. Noonan M, Ballinger R, Black R. Peer and faculty mentoring in doctoral education: Definitions, experiences, and expectations. Int J Teaching Learning Higher Educ. 2007;19(3):251-262.

21. Creswell JW. Qualitative Inquiry \& Research Design: Choosing Among Five Approaches, 3e. Thousand Oaks: Sage; 2013.

22. Merriam SB. Qualitative Research: A Guide to Design and Implementation. San Francisco: Jossey Bass; 2009.

23. Shenton AK. Strategies for ensuring trustworthiness in qualitative research projects. Educ Inform. 2004;22:63-74.

24. Nottingham SL, Mazerolle SM, Barrett JL. Promising and experienced investigators' experiences participating in the National Athletic Trainers' Association foundation research mentor program. J Athl Train. 2017;52(4):368-76. [PMID: 28318314]

25. Pitney W, lisley P, Rintala J. The Professional Socialization of Certified Athletic Trainers in the National Collegiate Athletic Association Division I Context. J Athl Train. 2002;37(1):8. [PMID: 12937446]

26. Kram K. Mentoring at Work: Developmental Relationships in Organizational Life. Glenview, IL: Scott Foresman; 1985.

27. Cotton J, Miller J, Ragins B. Marginal mentoring: The effects of type of mentor, quality of relationship, and program design on work and career attitudes. Acad Manage J. 2000;43(6):1177-94.

28. Kram K. Phases of the mentor relationship. Acad Manage J. 1983;26(4):608-25.

29. Nottingham SL, Mazerolle SM, Barrett JL. Effective characteristics of formal mentoring relationships: The NATA Foundation research mentor program. Athl Train Educ J. 2017:12(4): 244-255.

30. Berk R, Mortimer R, Walton-Moss B, Yeo T. Measuring the effectiveness of faculty mentoring relationships. Acad Med. 2005;80(1):66-71. [PMID: 15618097]

31. Zeind C, Zdanowicz M, MacDonald K, Parkhurst C, King C, Wizwet P. Developing a sustainable faculty mentoring program. Am J Pharm Educ. 2005;69(5):1-13. 